\title{
The Fate of Diazinon Applied to Thatched Turf ${ }^{1}$
}

\author{
B. E. Branham and D. J. Wehner ${ }^{2}$
}

\begin{abstract}
Diazinon [0,0-diethyl-0-(2-isopropyl-6-methyl-4-primidinyl) phosphorothioate] is widely used to control turfgrass insect pests. Poor control of soil-inhabiting insects has been found where diazinon has been applied to thatched turfgrass stands. The purpose of this study was to evaluate the environmental fate of diazinon applied to turfgrass stands. A microecosystem was used to follow the fate of radiolabeled diazinon surface applied to Kentucky bluegrass (Poa pratensis L.) turfs, with or without a thatch layer, growing on Flanigan silt loam (fine, montmorillonitic, mesic Aquic Argiudoll) irrigated daily or every 4 days. Loss of diaxinon by volatilization, leaching, and degradation accompanied by release of ${ }^{14} \mathrm{CO}_{2}$ or incorporation of label into soil compounds was measured. The most degradation of parent compound occurred on turf containing a thatch layer irrigated daily where only $7 \%$ of the applied diazinon remained after 3 weeks. Between 32 and $47 \%$ of the parent compound remained in either turf with thatch irrigated every 4 days or turfs without thatch. The majority of the diazinon $(96 \%)$ remained in the top $10 \mathrm{~mm}$ of the turf profile regardless of whether this was thatch or soil. In the presence of thatch, there was an accelerated rate of diazinon degradation as measured by release of ${ }^{14} \mathrm{CO}_{2}$ from the two position on the pyrmidine ring. Increasing irrigation frequency on the thatched turf did not cause an increase in leaching but did increase diazinon breakdown. The results of the study suggest that where thatch is present, reduced control of insects is due both to a failure of the insecticide to move through the thatch and an increased rate of degradation.
\end{abstract}

Additional index wordst Volatilization, Leaching, Environment.
THE plant-thatch-soil continuum has a major effect turfgrass stands. Thatch is defined as a tightly intermingled layer of dead and living stems and roots that develops between the zone of green vegetation and the soil surface (1). In order to maximize the efficacy of pesticides aimed at controlling soil-borne insects, it is important to understand how soil properties and the presence of thatch affect the rate and avenues by which pesticide dissipation occurs. Diazinon $[O-O$-diethyl- $O$ (2-isopropyl-6-methyl-4-pyrimidinyl) phosphorothioate] is a major insecticide used to control the larvae of several turfgrass insect pests (Cyclocephaca spp. and Popilla japonica). Irrigation after application of this insecticide is recommended. The presence of thatch has been shown to affect behavior of pesticides applied to turfgrass stands and specifically has been implicated

\footnotetext{
${ }^{1}$ Contribution of the Horticulture Dep., Univ, of Illinois. This study was part of project $65-356$ of the Illinois Agric. Exp. Stn., Univ. of Illinois, Urbana, IL 61801. Received 12 Mar. 1984. Published in Agron. J. 77:101-104.

2 Former graduate research assistant, currently assistant professor Crop and Soil Sci. Dep., Michigan State Univ., East Lansing, MI 48824 and assistant professor Horticulture Dep., Univ. of Illinois, Urbana, IL 61801.
} 
in changing the efficacy of diazinon in field studies (11).

The half-life of diazinon in soil has been reported by a number of authors $(3,5,6,9,10)$ to be between 7 and 56 days. The effect of a thatch layer on the halflife of diazinon has not been determined. Niemczyk et al. (12) showed that diazinon was intermediate in binding strength among the organophosphorus insecticides commonly used in turf. Konrad et al. (8) found that diazinon was rapidly adsorbed from solution by soil particles with degradation occurring in the adsorbed state and that the rate of degradation was closely correlated to the extent of initial adsorption.

The purpose of this research was to determine how thatch affects the degradation rate and avenues of loss of diazinon from a turfgrass sward by applying radiolabeled diazinon to turfs with and without a thatch layer and monitoring pesticide leaching, volatilization, and metabolism. The treated turfs were irrigated with two different application frequencies to determine the influence of this parameter on pesticide fate. Microecosystems (2) were used to study the movement and transformation of the labeled pesticide.

\section{MATERIALS AND METHODS}

The microecosystem used in this research is described in detail by Branham et al. (2). Briefly, the system consisted of a brass base that held an intact sample of turf, $30.5 \times 30.5$ $\times 5 \mathrm{~cm}, \mathrm{~L} \times \mathrm{W} \times \mathrm{H}$. The base was covered by a glass atmospheric chamber. In the bottom of the base was a porous ceramic plate which was connected to a vacuum pump that applied a tension of up to $50 \mathrm{kPa}$ to the plate to simulate leaching. The air stream passing through the atmospheric chamber was directed through trapping systems to remove volatilized and metabolized diazinon and ${ }^{14} \mathrm{CO}_{2}$ from the degradation of diazinon.

In this research, eight microecosystems were housed in a growth chamber set to provide a temperature inside the microecosystems of $21^{\circ} \mathrm{C}$ for $12 \mathrm{~h}$ with a light irradiance of $0.204 \mathrm{~W} \mathrm{~m}^{-2}$ and a night temperature of $16^{\circ} \mathrm{C}$. Irrigation was applied with overhead nozzles at a rate of $0.5 \mathrm{~cm}$ over a 15 min application period and the vacuum pump connected to the base of the microecosystems was set for a suction of $40 \mathrm{kPa}$. The four treatments $(2 \times 2$ factorial) consisted of turf without a thatch layer irrigated daily or every 4 days and turf with an existing $25 \mathrm{~mm}$ thatch layer irrigated daily or every 4 days. All treatments were replicated twice and consisted of field-grown Kentucky bluegrass (Poa pratensis L.) with or without a thatch layer growing on a Flanagan silt loam (fine, montmorrilonitic, mesic Aquic Argiudoll) with a pH of 5.7,2.8\% organic matter, and CEC of 14.8 $\mathrm{cmol}(\mathrm{p}+) \mathrm{Kg}^{-1}$. The turfs were allowed to equilibrate in the microecosystems for 3 days prior to the application of the radiolabeled pesticide.

Diazinon was applied as a $2 \%$ granule formulated on a $40 / 60$ mesh corn cob carrier. The rate of application was $4.89 \mathrm{Kg}$ active ingredient per hectare with enough ${ }^{14} \mathrm{C}$ diazinon, labeled in the two position of the pyrimidine ring to provide $0.15 \mathrm{mBq}$ per treatment. The specific activity of the ${ }^{14} \mathrm{C}$-diazinon formulation was $68.45 \mathrm{kBq} \mathrm{g}^{-1}$. Irrigation was applied immediately after diazinon application.

\section{Diazinon Analysis}

Five randomly chosen $1.9 \mathrm{~cm}$ diam cores were collected from the turf profile in each microecosystem at $0,7,14$, and 21 days after diazinon application. The cores were sectioned into the 0 to 10,11 to 30 , and 31 to $50 \mathrm{~mm}$ layers. The soil and/or thatch from the same depth interval was combined and frozen to $-10^{\circ} \mathrm{C}$ until analysis.

The soil and thatch samples were divided into subsamples to determine the dry weight of the sample and the amount of diazinon remaining in the soil. Extraction of the diazinon and metabolites from the soil and thatch was based on a method of Eberle and Novak (4). The residue from the extraction procedure was taken up in 2 to $4 \mathrm{~mL}$ of high pressure liquid chromatography (HPLC) grade methanol. An $0.5 \mathrm{~mL}$ aliquot was counted for total ${ }^{14} \mathrm{C}$ radioactivity and the remaining solution was filtered through a $0.2 \mu \mathrm{m}$ filter, placed in a $1 \mathrm{~mL}$ serum vial, capped, and stored at $-10^{\circ} \mathrm{C}$ until analysis by HPLC. The soil residue remaining from the extraction was dried and a subsample was combusted in a Packard oxidizer to determine the amount of unextractable radioactivity.

\section{Analysis of Volatilized Compounds}

A solid adsorbent (Chromosorb 101, Alltech and Associates) was used to trap the volatilized diazinon and metabolites because of its high adsorbtivity for organic compounds combined with a lack of retentive capacity for water. The trapping method, adapted from Pellizzari et al. (13), consisted of placing $5 \mathrm{~g}$ of Chromosorb 101 in an open-ended $7 \mathrm{~mm}$ diam glass tube. The tube was placed in the air scrubbing line at the outlet port of the model ecosystem atmospheric chamber. The trapping material was changed at 1,7 , and 21 days after application of diazinon. The diazinon was recovered from the trapping material by elution with hexane. The hexane was removed by flash evaporation and the residue was treated as described for the diazinon and metabolites extracted from the soil.

Released ${ }^{14} \mathrm{CO}_{2}$ was trapped in two bubbling tubes containing $1 \mathrm{M} \mathrm{NaOH}$ connected in series each to the outlet line of the atmospheric chamber. The traps were changed every day during the first 6 days of the experiment and then every other day until the experiment was concluded at 21 days. A $1 \mathrm{~mL}$ subsample of the trapping solution was placed in $15 \mathrm{~mL}$ of Aquasol and counted to determine radioactivity.

Leachate samples were collected prior to each irrigation, the volume measured, and the samples were stored in polyethylene bottles at $1^{\circ} \mathrm{C}$. A tube filled with Chromosorb 101 was placed in the vacuum line leading to each leachate trapping flask to remove any diazinon that might be volatilized from the leachate by the action of the applied vacuum. The Chromosorb 101 was handled as previously described.

The leachate was tested for gross radioactivity by placing a $5 \mathrm{~mL}$ aliquot in $15 \mathrm{~mL}$ Aquasol and counting for $20 \mathrm{~min}$ in a liquid scintillation counter. The remaining leachate was extracted twice with dichloromethane to determine if diazinon or its metabolites were present. The dichloromethane extracts were treated as described for the diazinon soil procedures.

\section{HPLC Analysis of Diazinon}

The column used in the diazinon analysis had dimensions of $250 \times 4.6 \mathrm{~mm}$ and was packed with a $5 \mu \mathrm{m}$ octadecylsilane material. The chromatography system consisted of a Beckman model 421 liquid chromatograph with a Hitachi model 155-10 UV-VIS detector.

A gradient was used to separate diazinon from two of its common metabolites, 2-(1'-hydroxy-1'-methyl)ethyl-4-methyl6-hydroxypyrimidine (G-31144) and 2-isopropyl-4-methyl6-hydroxypyrimidine (G-27550) (Ciba-Geigy Corp., Research Triangle Park, NC). The injection of a $100 \mu \mathrm{L}$ sample was made into a mobile phase of $25: 75\left(\mathrm{Ch}_{3} \mathrm{OH}: \mathrm{H}_{2} \mathrm{O}\right)$. After $3 \mathrm{~min}$, the mobile phase was increased to $85: 15\left(\mathrm{CH}_{3} \mathrm{OH}: \mathrm{H}_{2} \mathrm{O}\right)$ over a 5 min period. The mobile phase was held at this composition for $21 \mathrm{~min}$. Diazinon eluted with a retention 
Table 1. Weekly summary for fate of radiolabeled diazinon applied to turfgrass stands and analysis of variance (ANOVA) for each aspect of pesticide fate.

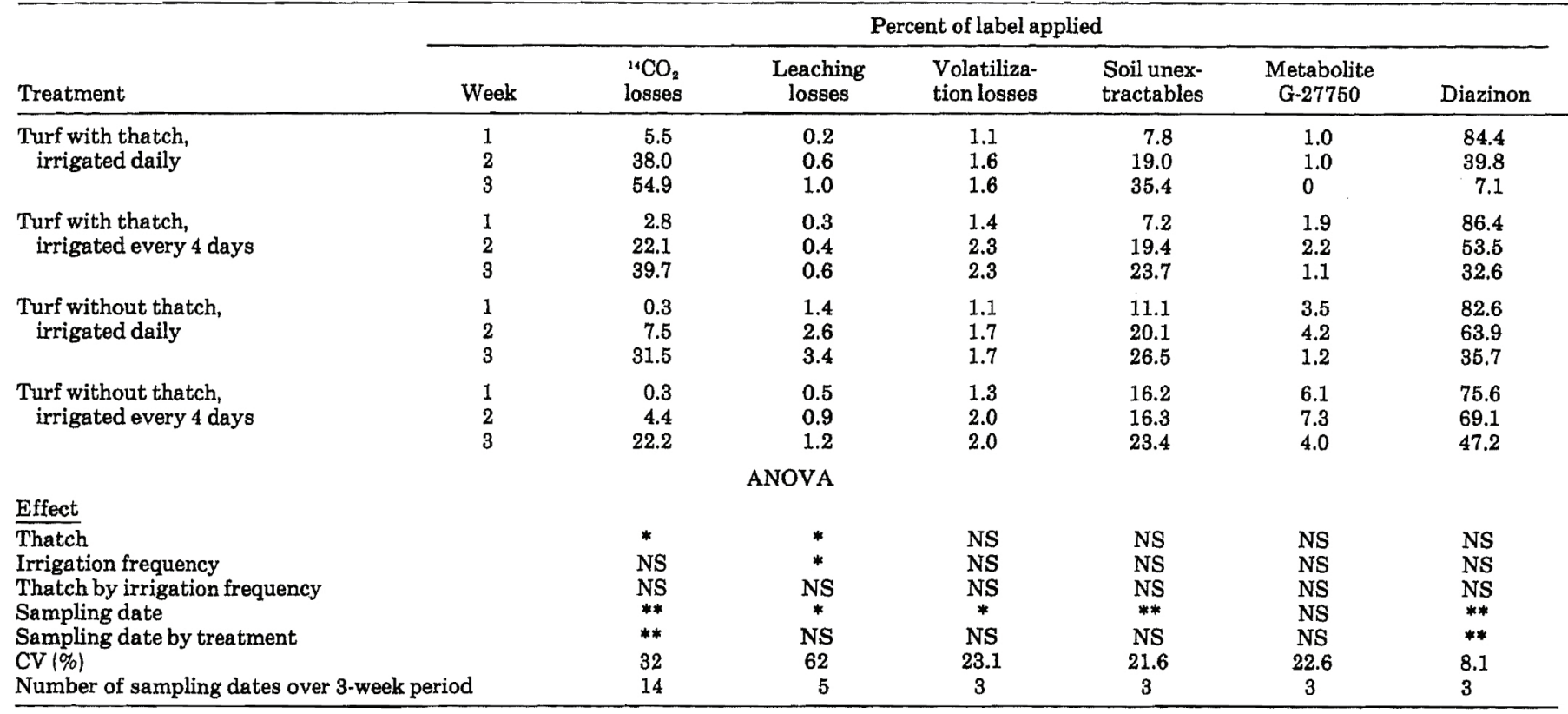

$*, * *, N S=$ significant at $P=0.05, P=0.01$, and not significant, respectively

$\dagger$ Analyzed as split-plot design with treatments $(2 \times 2$ factorial, thatch and irrigation frequency) as main plots and sampling date as subplots.

time of 20.7 min while G-31144 and G-27550 had retention times of 5.1 and $8.4 \mathrm{~min}$, respectively. The three compounds were collected into scintillation vials into which $15 \mathrm{~mL}$ of Aquasol were added for assay of radioactivity.

All data were subjected to an analysis of variance (ANOVA) using a split-plot design with treatments $(2 \times 2$ factorial, thatch, and irrigation frequency) as the main plot and sampling date as the subplot. A separate ANOVA was run for each avenue of pesticide loss (e.g., leaching losses, volatilization losses, pesticide metabolism in the form of released ${ }^{14} \mathrm{CO}_{2}$, soil unextractable radioactivity and the amount of metabolite G-27550) as well as for the percent of parent diazinon remaining in the turf. The treatment sum of squares was partitioned to test the effect of thatch, irrigation frequency, and the thatch by irrigation frequency interaction. Graphs were generated to demonstrate significant treatment by sampling date interactions.

\section{RESULTS AND DISCUSSION}

A weekly summary of the fate of radiolabeled diazinon applied to turfs in the microecosystems and the results of the ANOVA for each aspect of pesticide fate and presented in Table 1. The ANOVA over the 3week period for percent diazinon remaining in the turf indicated a significant sampling date by treatment interaction. Figure 1 illustrates the differential rates of diazinon loss due to the presence of thatch and variable irrigation frequency. By the 2nd and 3rd weeks, more pesticide was lost from turfgrass swards containing a thatch layer than from those without a thatch layer. By the 3rd week, loss was accelerated with increased irrigation frequency.

Degradation, volatilization, and leaching of the diazinon were measured. The main avenues of pesticide loss were the degradation of the parent compound with the release of ${ }^{14} \mathrm{CO}_{2}$ and the incorporation of the labeled ${ }^{14} \mathrm{C}$ into nonextractable soil compounds. There were no significant treatment effects in regard to the amount of ${ }^{14} \mathrm{C}$ tied up in nonextractable compounds.

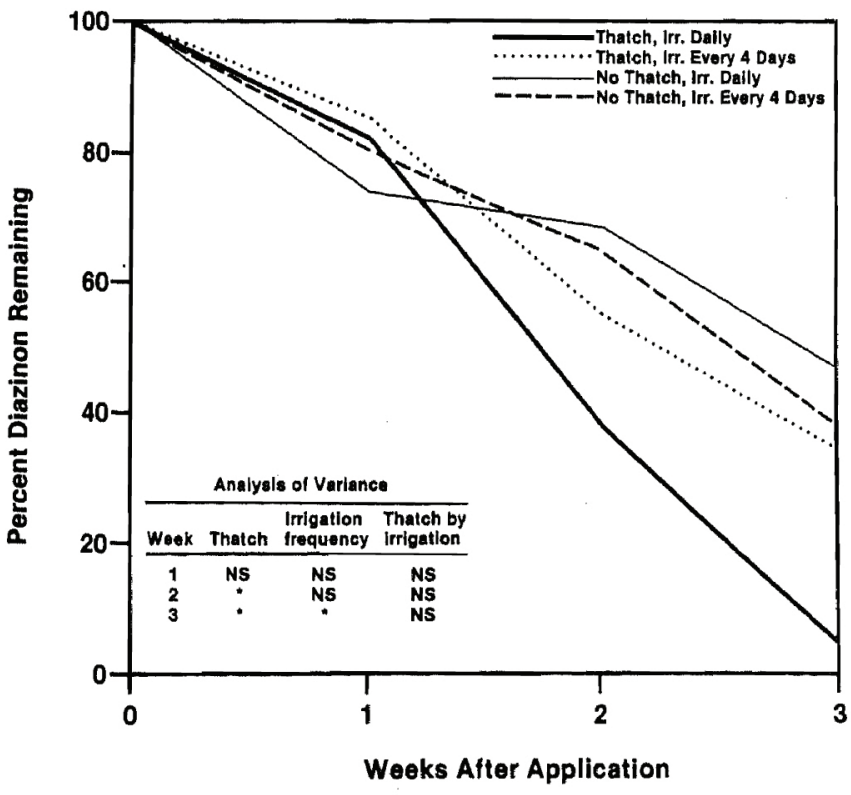

Fig. 1. Percent diazinon remaining in turf over 3-week period. *, NS Significant at $\mathbf{P}=\mathbf{0 . 0 5}$ and nonsignificant, respectively.

The diazinon used in this research was labeled in the pyrimidine ring so that release of ${ }^{14} \mathrm{CO}_{2}$ indicates total breakdown of the molecule while loss of insecticidal activity will occur with any change in the structure of the parent molecule. Because the sampling date by treatment interaction for the amount of label released in the form of $\mathrm{CO}_{2}$ was significant, a graph (Fig. 2) was constructed to illustrate the loss of $\mathrm{CO}_{2}$ from each turf.

Degradation of diazinon occurs by chemical hydrolysis (8) and microbial decomposition (7). The relative importance of each path has not been determined. No definitive answers can be found from this 


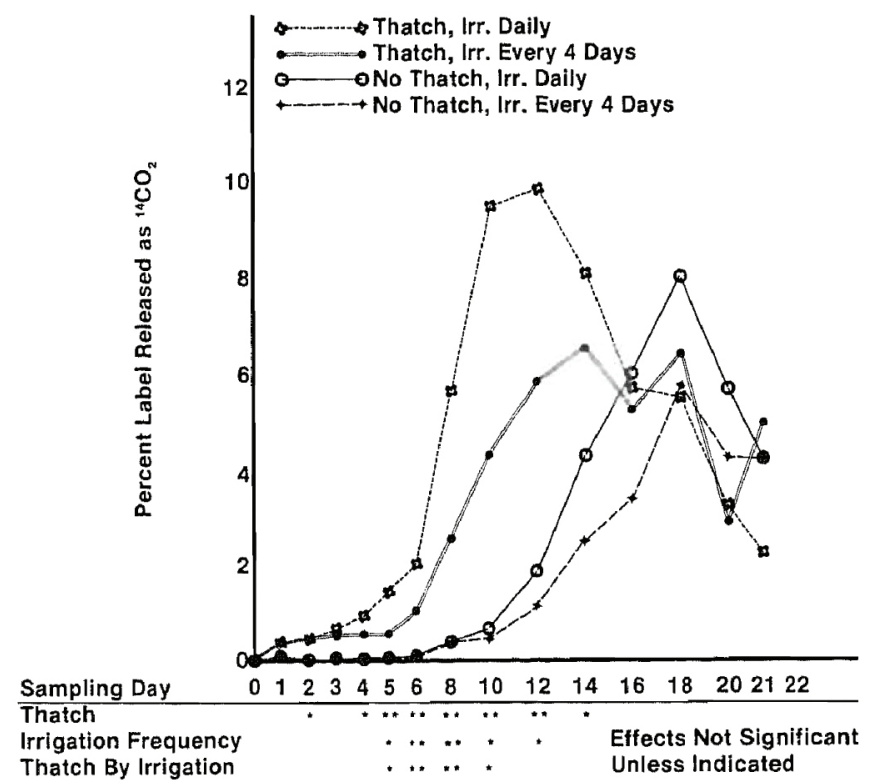

Fig. 2. Loss of ${ }^{14} \mathrm{CO}_{2}$ from each microecosystem over 21-day sampling period and analysis of variance for each sampling day. * ** $=$ Significant at $\mathrm{P}=0.05$ and 0.01 , respectively.

work since the location of the label is inside the pyrimidine ring and diazinon has already lost its insecticidal properties by the time the ${ }^{14} \mathrm{CO}_{2}$ is liberated.

The total amount of pesticide lost by leaching through the $50 \mathrm{~mm}$ profile was very small but was influenced by the presence of thatch and irrigation frequency. The majority (96\%) of diazinon was found in the 0 to $10 \mathrm{~mm}$ sampling depth regardless of whether there was a thatch layer on the soil surface. The failure of diazinon to move through thatch could affect the control of soil-inhabiting insect pests since they may reside below the thatch layer.

Volatilization accounted for a small amount of the total diazinon lost from the site of application. In this research, the initial irrigation was applied immediately after pesticide application. Volatilization losses could be larger under other circumstances. The amount of compound G-27550 present in the 0 to $10 \mathrm{~mm}$ layer was not affected by the presence of thatch or irrigation frequency. The total amount of this compound present would be a function of the rate of its degradation as well as the rate and pathway of diazinon degradation. Although the amount of metabolite found in the samples without thatch was higher than that found with thatch, there was no significant difference due to the presence of thatch.

The variable and sometimes poor control of soilborne insects when a thatch layer is present is probably due to a combination of increased adsorption within the thatch layer, as illustrated by the reduced amount of leaching, along with an increased degradation rate. It is difficult to ascertain which of these two phenomena are more important, however, the information presented in Fig. 1 may offer some insight. The amount of diazinon remaining after 1 week in turf without thatch was not significantly different from the amount in turf with thatch. Subsequently, the rate of disappearance of diazinon in thatched turf exceeds that found in turf without thatch and is accompanied by a concomitant increase in ${ }^{14} \mathrm{CO}_{2}$ production (Fig. 2). There was a significant effect of thatch on $\mathrm{CO}_{2}$ production during sampling Days 4 to 14 while the effect of irrigation frequency was significant during Days 5 to 12 . Thus, it appears that degradation is facilitated with frequent irrigation in thatch layer to such an extent that there may not be enough diazinon present for a long enough period of time to achieve control of the target pest.

\section{ACKNOWLEDGMENTS}

The authors wish to acknowledge the Chicago District Golf Foundation for financial support of this research and the Ciba-Geigy Corporation for supplying radiolabeled pesticide.

\section{REFERENCES}

1. Beard, J.B. 1973. Turfgrass science and culture. Prentice-Hall, Inc. Englewood Cliffs, NJ.

2. Branham, B.E., D.W. Wehner, W.A. Torello and A.J. Turgeon. 1984. A microecosystem for fertilizer and pesticide fate research. Agron. J. 77:176-180.

3. Bro-Rasmussen, E. Noddegaard, and K. Voldum-Clausen. 1968. Degradation of diazinon in soil. J. Sci. Food Agric. 19:278-281.

4. Eberle, D.O., and D. Novak. 1969. Fate of diazinon in fieldsprayed agricultural crops, soil, and olive oil. JOAC 52(5):10671073.

5. Getzin, L.W. 1968. Persistence of diazinon and zinophos in soil: effects of autoclaving, temperature, moisture, and acidity. J. Econ. Entomol. 61(6):1560-1565.

6. Getzin, L.W., and I. Rosefield. 1966. Persistence of diazinon and zinophos in soils. J. Econ. Entomol. 59(3):512-516.

7. Gunner, H.B., and B.M. Zuckerman. 1968. Degradation of diazinon by synergistic microbial action. Nature 217:1183-1184.

8. Konrad, J.G., D.E. Armstrong, and G. Chesters. 1967. Soil degradation of diazinon, a phosphorothioate insecticide. Agron. J. 59:591-594

9. Malone, C.R., A.G. Winnett, and K. Helrich. 1967. Insecticide induced responses in an old field ecosystem: persistence of diazinon in soil. Bull. Environ. Contam. Toxicol. 2:83-89.

10. Miles, J.R.W. C.M. Tu, and C.R. Harris. 1979. Persistence of eight organophosphorous insecticides in sterile and nonsterile mineral and organic soils. Bull. Environ. Contam. Toxicol. 22:312-318

11. Niemczyk, H.D., and D.M. Dunbar. 1976. Field observations, chemical control, and contact toxicity experiments on Ataenius spretulus, a grub pest of turfgrass. J. Econ. Entomol. 69(3):345348.

12. -H:R. Krueger, and K.O. Lawrence. 1977. Thatch influences movement of soil insecticides. Ohio Rep., 62(2):26-28.

13. Pellizzari, E.D., J.E. Bunch, R.E. Berkley, and J. McRae. 1976. Collection and analysis of trace organic vapor pollutants in ambient atmospheres. The performance of a tenax GC cartridge sampler for hazardous vapors. Anal. Lett. 9(1):45-63. 